\title{
Review of Energy Storage Technologies for Compressed-Air Energy Storage
}

\author{
Ibrahim Nabil, Mohamed Mohamed Khairat Dawood", Tamer Nabil \\ Mechanical Engineering Department, Suez Canal University, Ismailia, Egypt \\ Email address: \\ Mohamed_Khairat@eng.suez.edu.eg (M. M. K. Dawood) \\ ${ }^{*}$ Corresponding author \\ To cite this article: \\ Ibrahim Nabil, Mohamed Mohamed Khairat Dawood, Tamer Nabil. Review of Energy Storage Technologies for Compressed-Air Energy \\ Storage. American Journal of Modern Energy. Vol. 7, No. 4, 2021, pp. 51-60. doi: 10.11648/j.ajme.20210704.12
}

Received: April 27, 2021; Accepted: May 19, 2021; Published: August 23, 2021

\begin{abstract}
Energy systems play a significant role in harvesting energy from several sources and converting it to the energy forms needed for applications in numerous sectors, e.g., utility, industry, building, and transportation. In the coming years, energy storage will play a key role in an efficient and renewable energy future; more than it does in today's fossil-based energy economy. There are different strategies for energy storage. Among these strategies, storage of mechanical energy via suitable media is broadly utilized by human beings. Mechanical energy storage systems (MESS) are among the utmost effective and sustainable energy storage systems. There are three main types of mechanical energy storage systems; pumped hydro, flywheel, and compressed air. This review discusses the recent progress in mechanical energy storage systems focusing on compressed air energy storage (CAES). It also discusses the advances and evolution in compressed air energy storage (CAES) technologies which improve the thermal process and incorporate CAES with other subsystems to improve system efficiency and compares these technologies in terms of their performance, capacity, response, and utilizations as well as the challenges facing CAES as emissions that may harm the environment, the consumption of fossil fuels or requiring certain geological formations then modifications and developments to overcome these challenges.
\end{abstract}

Keywords: Mechanical Energy, Energy Storage, Compressed Air Energy Storage, Energy Storage Technologies and Applications

\section{Introduction}

Cumulatively, over years energy consumption has been growing significantly. According to the published statistics by the International Energy Agency (IEA), about 13,371 Million Tons of Oil Equivalent (Mtoe) of energy is supplied worldwide in 2012. This is near $10 \%$ and $119 \%$ higher than the statistics in 2009 and 1973 values respectively. Despite there is an increasing tendency in the global energy supply, the percentage share of fossil fuel has been declining gradually due to the advances in renewable energy systems [1].

Energy storage is a crucial link in energy supply chain. For example, actually there is no system that is $100 \%$ thermodynamically efficient. The energy losses in different systems happen in the Energy storage has many benefits. It is important in energy management to reduce energy wastage and maximize the efficiency of energy utilization of process systems $[2,3]$.
Energy storage is expected to play a substantial role as the world moves to a low carbon economy somewhere more energy is predicted to be produced from renewable resources. Renewable energy resources, especially solar and wind are facing a main challenge as they occur intermittently which creates unreliable steady energy supply. This can be attained by storing the excess energy produced when the renewable resources are available and re-use it again when the renewable resources are not available [1].

\section{Importance of Energy Storage}

Energy storage has lots of benefits. Storage of secondary energy systems as electricity and heat is important to reduce the amount of primary energy forms (fossil fuels) that have been consumed to generate them. This results in not only decrease $\mathrm{CO}_{2}$ and other greenhouse gas emissions that lead to global warming [5] but also help to preserve fossil fuels which 
are supposed to be exhaustible. It can also play a essential role in increasing the use of renewable, clean and irregular energy resources such as wind energy, solar energy, and marine tidal current to the grid as well as help in load shifting [4]. Energy storage helps in the planning of power system, its operation and frequency regulation [4, 5]. It helps to keep energy systems stability, improve power quality in micro-grid systems in addition match demand with supply [6].

There are many technologies used for energy storage drives. These technologies can be generally categorized according to the purpose for which the energy is stored. They include: thermal energy storage and electrical energy storage. Figure 1 shows the diverse classes of energy storage technologies. From the figure, it is shown that the technologies in which energy is stored in the form of thermal energy and released in the thermal form such as ice/chill water storage are categorized as thermal energy storage technologies while those in which the energy is stored in the form of thermal but released as electrical energy such as liquid air energy storage are categorized as electrical storage. In this review the emphasis is on mechanical energy storage [1].

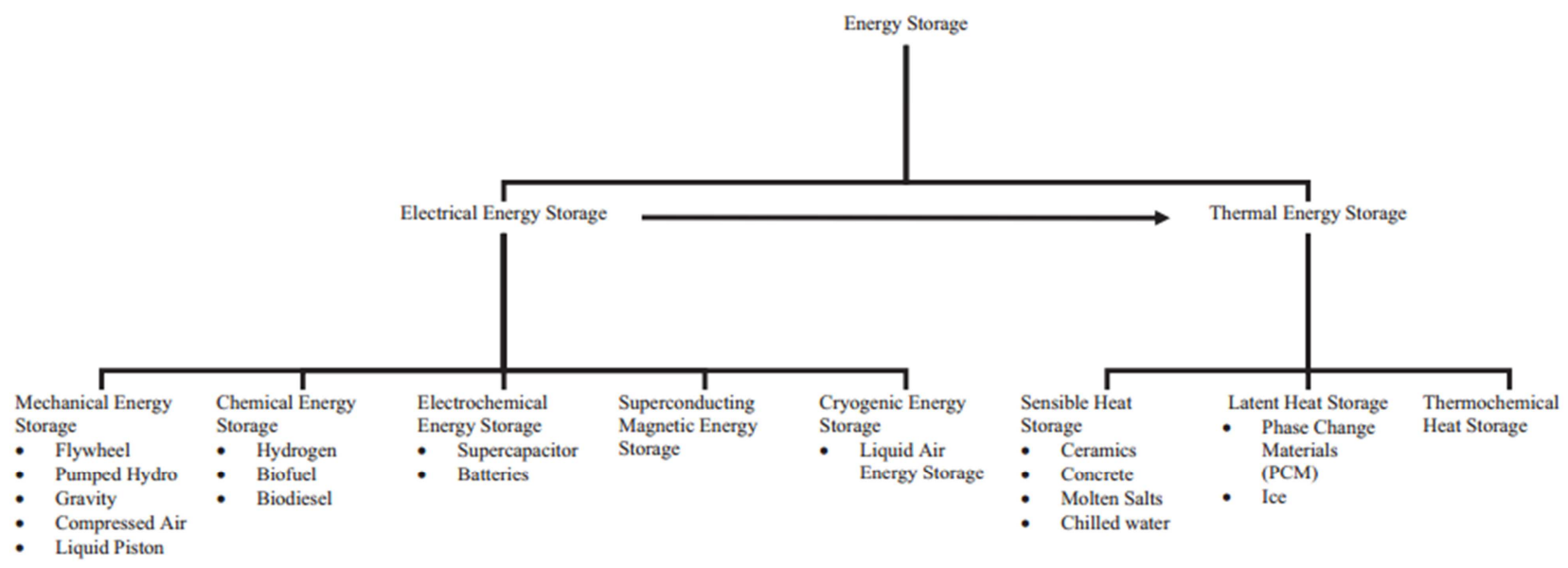

Figure 1. Energy storage technologies classification [7].

\section{Mechanical Energy Storage Systems}

Mechanical energy storage systems (MESS) stored mechanical energy as kinetic energy or dynamic energy. They have main advantage as they are fast with direct release of the stored mechanical energy [8].

MESS are classified mainly to Pump hydro energy storage (PHES); compressed air energy storage (CAES) and Flywheel energy storage (FES) [9, 10].

\subsection{Pump Hydro Energy Storage}

PHES stored energy through pumping water from a low tank to a high tank; the low tank is altitude wise much lower than the high one [11]. In addition to the two tanks a PHES has an electric motor to be used as a pump while charging or used as a power generator while discharging [4]. The amount of the stored energy is proportionate to the altitude difference between the two tanks as well as the amount of stored water [5]. Efficiency of PHES Storage system varies between $65 \%$ to $85 \%[1,5,12]$.

\subsection{Compressed Air Energy Storage}

Operation concept of CAES is established on compressing air using inexpensive energy; generated on low energy demand times; and its future release onto a turbine for the operation of an electric generator $[4,5]$. The first CAES system initiated operating in 1978 in Germany (290 MW). Then it was followed by the Mclntoch CAES plant in Alabama (110 MW) in 1991. These two systems are the only operating CAES globally $[12,13]$.

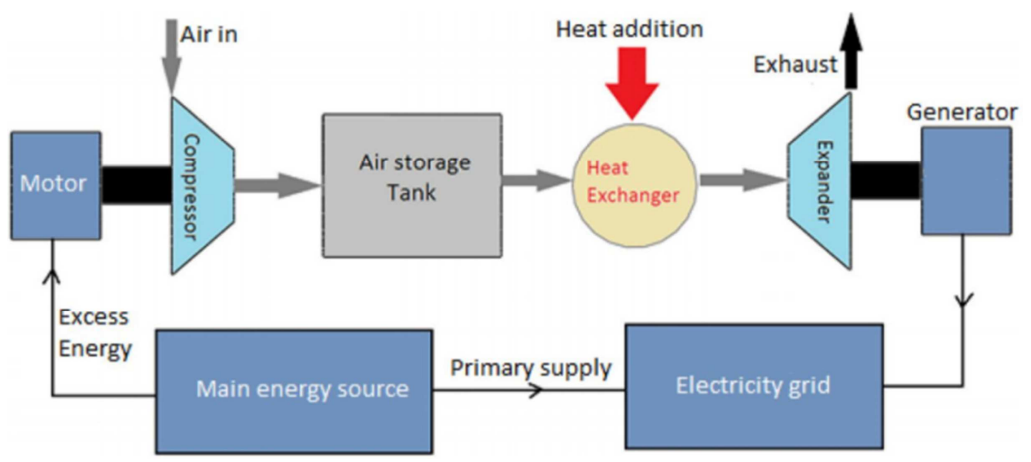

Figure 2. Chart diagram of a conventional CAES. 
A compressed air energy storage system (CAES) is composed of a compressor; a storage tank and a turbine. The turbines used in CAES for generating power are established on Brayton's thermodynamic cycle [14] Schematic diagram of a conventional CAES is displayed in figure 2. The operation of a CAES is much like to a common turbine. At time of charging the generator works as a motor supplying power to the air compressor. At time of discharging the compressed air is place in the combustion chamber and then is released on the turbine. The turbine role is to move the electric power generator. Although CAES release $\mathrm{CO}_{2}$ they can provide three times more electric power to the grip than a common turbine for power generator; however consuming the same among of fuel [4].

Compressed air energy storage (CAES) is a commercial, utility-scale system that offers long-duration energy storage with fast ramp rates and good part-load operation. It is considered a promising storage technology for balancing the large-scale use of renewable energies, such as wind and solar power, into electric grids [12]. The process diagram of a CAES is shown in Figure 3

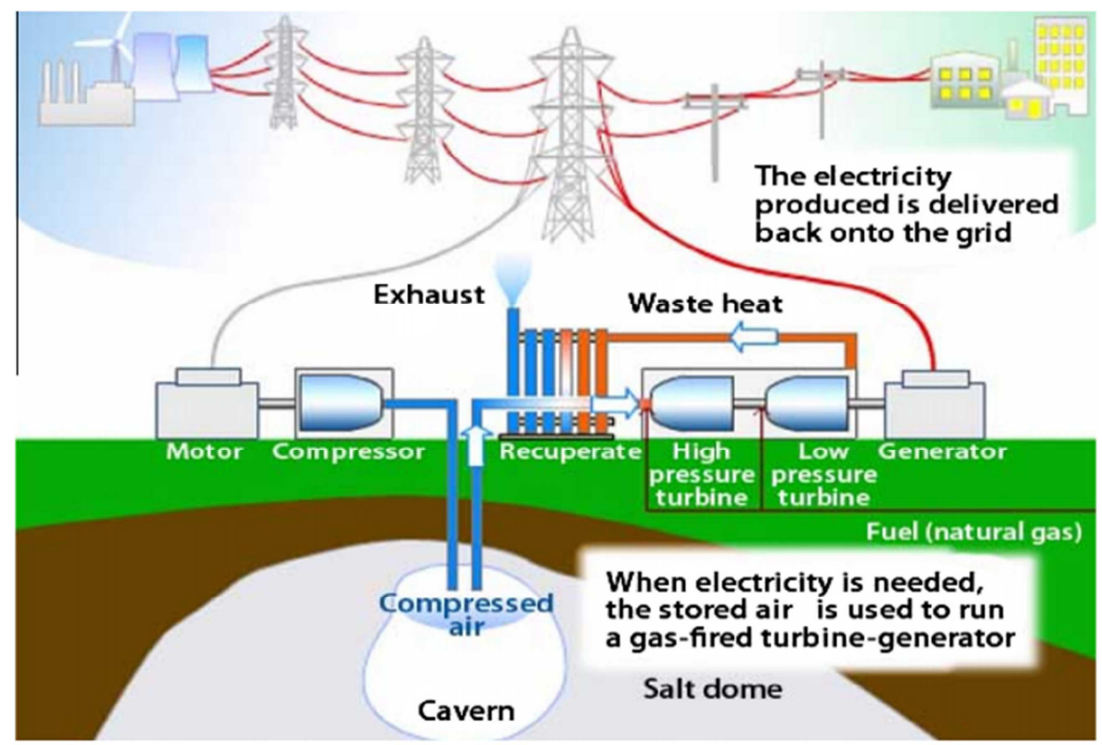

Figure 3. The process diagram of a CAES.

\subsection{Flywheel Energy Storage}

The kinetic energy is stored in a FES by enhancing the revolutions per minute of a flywheel [4, 5, 15]. Flywheels can be connected to an electric power generator; which transform kinetic energy to electric [4, 5]. The energy capacity of a flywheel is proportionate to its mass and the square of its speed. The capacity of a FES differs according to the durability of the flywheel's material [5]. The determinant factors of the energy density of a FES are the flywheel's geometry and material [4]. FES Storage proficiency is approximately $90 \%$ [5]. Flywheels are classified as low rpm flywheels and high rpm flywheels. Low rpm flywheels are those who reach less than $6000 \mathrm{rpm}$. On the other hand high rpm flywheels can reach $105 \mathrm{rpm}$ [5.15].

Table 1. Advantages - Disadvantages of MESS and their use in RES systems.

\begin{tabular}{llll}
\hline MESS & Advantages & Disadvantages & Use in RES system \\
\hline PHES & Quick respond time & High construction cost & Wind parks, hydro electrics \\
CAES & Limited self-discharge & $\mathrm{CO}_{2}$ emission & Wind parks, hydro electrics \\
FES & Low maintenance cost & High self-discharging & Wind parks \\
\hline
\end{tabular}

Table 2. Technical and financial characteristics of MESS.

\begin{tabular}{llll}
\hline MESS & Capacity (MW) & Lifetime (years) & Capital cost (€/kWh) \\
\hline PHES & $100-5000$ & $40-60$ & $4.5-90$ \\
CAES & $3-400$ & $20-60$ & $1.8-90$ \\
FES & 0.25 & 15 & 4487 \\
\hline
\end{tabular}

\subsection{Compressed-Air Energy Storage (CAES)}

CAES systems store energy as a compressed air in underground caverns, and the energy is then supplied to electrical networks through a conversion process. The air is usually compressed into an underground reservoir, which enables the storage of energy in a 'pressure gradient'; the energy is generated through a combustion process in order to operate an expansion turbine which turns an electrical generator [16]. The thermal energy generated during air 
compression (charging) is released directly to the atmosphere, and during operation of decompression (discharging), the air necessities to be reheated, usually with a fuel [17]. The Schematic diagram of a CAES is shown in Figure 4.

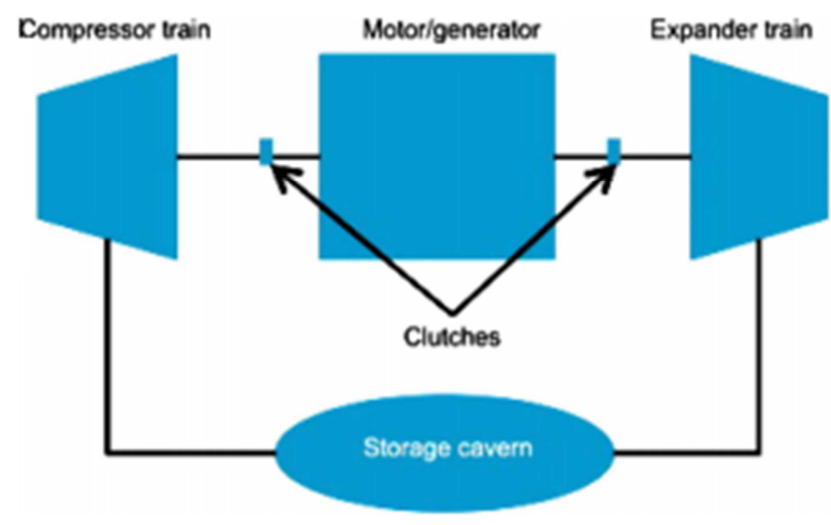

Figure 4. Schematic diagram of CAES [16].

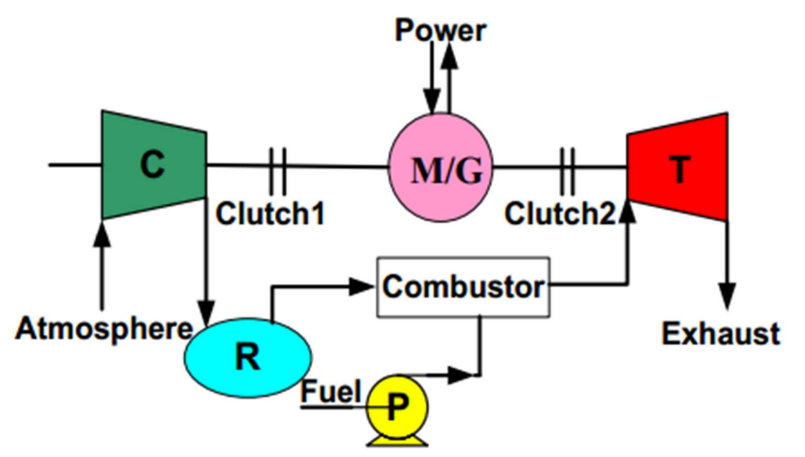

Figure 5. Schematic diagram of CAES system (C-Compressor, G-T-Gas turbine, $M / G-$ Motor/Generator, $P-P u m p, R-$ Reservoir).

\section{Components of CAES}

A whole CAES system consists of primary components: (1) compressors; (2) expanders; (3) air reservoirs; (4) combustor; (5) motor/generator; (6) controlling system; (7) other auxiliary equipment, such as fuel tanks, pipe connection and so on.
Compressors, expanders and air reservoirs play crucial roles in the whole CAES system construction, and the descriptions of each are presented below.

(1) Compressors and Expanders:

Compressors and expanders are planned according to the used applications and the designed storage pressure of the air. The level of compressed air may reach $30 \mathrm{MPa}$ in a vehicle cylinder on the other hand around $8 \mathrm{MPa}$ in a large scale CAES system for which multi-stage compressors are used. $[18,19]$. Similarly, the steam turbines in Huntorf are utilized for the first-level expansion from 4.6 MPa to $1.1 \mathrm{MPa}$; and gas turbines are used for the second-level expansion from 1.1 MPa to atmospheric pressure, in which the working medium is flue gas released from the combustion of the air and fuel.

(2) Air Reservoirs

Large volume air reservoirs are needed for large scale CAES systems, so manufacturing large storage containers is a vital issue. This is the reason for using underground caverns for storage in the existing operational CAES plants, in particular, salt caverns. Recently, underground salt layers, underground hard rock layers, and underground porous rock layers considered the main suitable geological formations. Table 3 displays the capital cost of an air reservoir for numerous storage media and plant configurations [19]. The cost is linked to the types of storage (containers/caverns), power rating and the duration. Consequently, in Table 3 , the cost of power related components such as turbine, expander etc. is presented as \$/unit power and the cost of storage components such as underground caverns and over ground cylinders is related to their capacity and presented as \$/unit energy stored. At the present time, the two commercial CAES storage systems plants that utilize underground salt caverns with storage capacities of 310,000 m3 (Huntorf) and 560,000 $\mathrm{m} 3$ (McIntosh), respectively. On the other hand there are some challenges that appear in the formation and maintenance of salt caverns such as rat holes, the damage triggered by small animals, the treatment of salt water, etc. [20, 21].

Table 3. Different storage media and plant configurations of air storage reservoir [4].

\begin{tabular}{llllll}
\hline Reservoir & Size $(\mathbf{M W e})$ & CPRC $\mathbf{( \$ / k W )}$ & CESC $\mathbf{( \$ / k W h )}$ & ST $(\mathbf{h})$ & TC $(\mathbf{\$} / \mathbf{k W e})$ \\
\hline Salt & 200 & 350 & 1 & 10 & 360 \\
Porous media & 200 & 350 & 0.1 & 10 & 351 \\
Hard rock & 200 & 350 & 30 & 10 & 650 \\
surface piping & 20 & 350 & 30 & 3 & 440 \\
\hline
\end{tabular}

Abbreviations: CPRC, Cost for Power-Related Plant Components; CESC, Cost for the Energy Storage Components; ST, "Typical” hours of Storage for a Plant; TC, Total Cost.

There are two main operation modes of an air reservoir, sliding-pressure operation and constant-pressure operation.

Sliding-pressure operation with a constant volume: in this operation the rising pressure results in a change of the pressure ratio of the compressors leading to an increase in losses which are irreversible. Also, there will be remnant air at the end of the discharge that consequently reduces the efficiency of the entire system.

Constant-pressure operation at both the charging and discharging stages: provides efficient system under the estimated conditions [21].

\subsection{Description of Compressed Air Energy Storage (CAES) Systems}

The concept of compressed air energy storage system is based mainly on compressing air and storing it in underground cavern or an abandoned mine when more 
energy is accessible and exceed the needed quantity. According to the energy demand, the stored compressed air is released to a turbine to generate electricity. Caverns may either be drilled in salt or rock formations, or utilizing existing cavities such as aquifer strata. Such geological formations do not exist all over and large steel tanks which are utilized to maintain high pressures are sometimes installed under the ground at a higher cost. Can be economically attractive due to their capacity of compressed air energy storage systems to shift time of energy use gives an economic advantage in addition to the need to balance the effects of intermittent renewable energy penetration in the grid [23].

On the other hand using the excess available energy to store liquefied air at cryogenic temperatures in low-pressure completely insulated reservoirs is another alternative. In comparison to compressed air, liquid air has much lower losses because it could be kept at moderate pressures. Consequently, it might be a superior option than compressed air for long-term storage systems. Liquid air has other advantages over compressed air as it is denser and with the opportunity to be stored in smaller reservoirs. For a specified quantity of liquefied air in a tank of $5000 \mathrm{~m}^{3}$, it is reported in a case study that the CAES volume was approximately $310,000 \mathrm{~m}^{3}$ [24]. When comparing between compressed air and liquefied air energy storage systems it indicated that a higher efficiency for the liquefied air energy storage systems [24]. To produce, the simplest approach to obtain liquid air when excess energy is existing is based on the Linde-Hampson cycle in which a JouleThompson effect valve is used for the expansion. Other variability of this cycle may also comprise cryogenic turbines for expansion (e.g., Claude and Collins cycles) which lower the operating pressures, and increase liquid air production amount as well as efficiencies [25].

While discharging, liquefied air is pumped to high pressure, evaporated and then heated to supply high pressure air. There are two resources for heat provision, from ambient temperature medium as air as well as from a highertemperature medium such as gases from natural gas combustion. The specific work output and the system efficiency can be improved through increasing the temperature, making it near equivalent to other energy storage technologies. Using air directly for combustion is an alternative to increase the temperature. The air, or gas, from a liquefied container can be expanded in turbines to generate electricity. To improve the system efficiency authors proposed various Methods to decrease liquefaction wastes and external energy requirements of regasification of liquefied air [26, 27, 28]. For instance, the use of the waste cooling power from the liquid air evaporation stage in other cycles (e.g., Rankine) can generate extra work and improve the efficiency of system to more than $80 \%$ [25].

The cooled air can be used as a heat sink in a Brayton cycle as well as in a cryogenic organic Rankine cycle. In a Brayton cycle, the generated heat during air compression before its liquefaction as waste heat could be stored and utilized to heat the air again as passing through turbines as well as to be as a source for heat. She et al. [26] propose a Brayton cycle that utilizes the heat from liquefaction of air and releases heat to the evaporator of a liquefied natural gas storage system, therefore coupling the two systems for better efficiency. The authors reported that system round-trip efficiency is around 70\%. Peng et al. [28] suggested packed beds as direct contact heat exchangers to accumulate the excess heat in the compression stage of liquefaction then release it to the air in the expansion stage during discharging process. Xie et al. [29] suggested that economic feasibility is improbable for liquefied air energy storage systems without the use of waste heat, and that increasing the feasibility with larger plant installations. Reliant on how heat is controlled and managed during compression as heat discharge and earlier to the expansion stage as heat intake, there are three different types of CAES: isothermal, diabatic and adiabatic. CAES system has a RTE of $85 \%$, with an expected life time of about 20-40 years; it is considered a suitable possibility for large-scale storage applications. There are many challenges that CAES systems face which includes the necessity for an underground cavern, dissipation of excess heat into the atmosphere, consuming fossil fuels, and production of pollutant emissions from the combustion processes [30, 31].

The diabatic-CAES system has been described above; however, recent technological efforts have led to development of the following systems

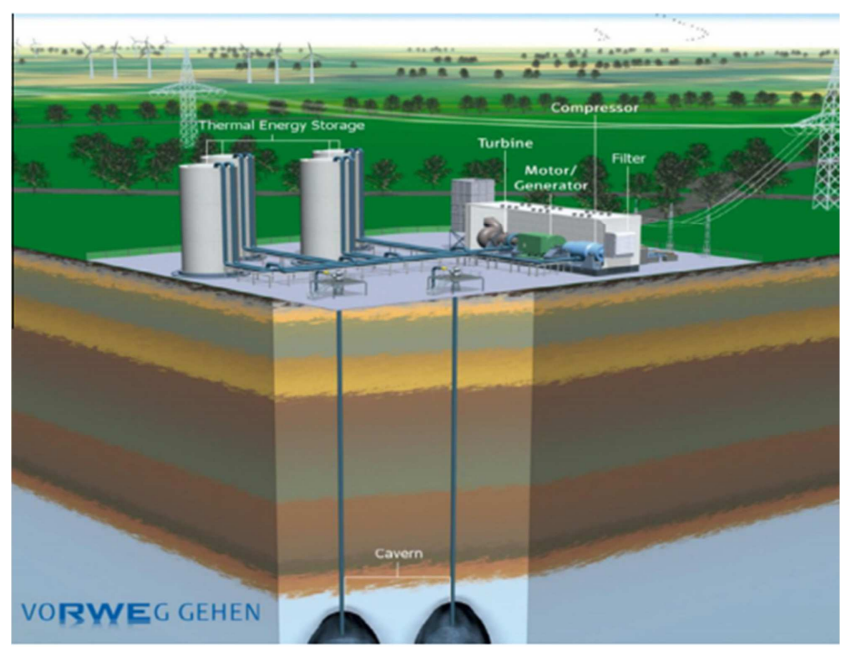

Figure 6. Diagram of the AA-CAES by RWE [33].

\subsection{Adiabatic-CAES}

Adiabatic-CAES was designed to remove the need for fuel in CAES technologies, this happens through storing the heat energy which generated during air compression, and then utilize it to reheat the air during its expansion $[30,31]$. In this condition, thermal energy storage (TES) system is replacing the combustion chamber in the conventional CAES. Adiabatic-CAES is predicted to be a promising technology because of its scalability, environmental - friendliness, hybrid storage advantage (CAES/TES) and great energy storage efficiency [32]; the removal of combustors and fossil 
fuels also makes it more economic than the conventional CAES. The main constituents of an adiabatic-CAES plant include compressor, TES, underground cavern and air turbine. These components can be configured into the needed storage scale. From the most suitable thermal energy storage materials in adiabatic-CAES system, Salt and concrete. The world's first adiabatic-CAES plant, stated to advanced adiabatic-CAES (AACAES) demonstration plant, is projected to go 'on stream' in Germany by 2016 , by RWE Power and its partners $[33,34]$. The aim of the project is to obtain system efficiencies of $70 \%$. The Advanced adiabaticCAES (AA-CAES) by Rheinisch-Westfälisches Elektrizitätswerk (RWE) is shown in Figure 6.

\subsection{Isothermal CAES}

Isothermal CAES this new technology tries to overcome particular challenges with conventional adiabatic- or adiabatic CAES [31], by elimination the need for fuel and 'high temperature' heat energy storage, which results in improved RTE of (70-80\%) and reducing the cost making it more economic. In this system, the air is compressed without any change in temperature, permitting minimal work for compression while maximizing the work required for expansion, through effective heat transfer with surroundings of the air vessel [32].

\subsection{Small-medium Scale CAES}

Small-medium scale CAES large-scale CAES plants usually require suitable geological formations for storing air [33, 34]. However, small-medium scale CAES, with a capacity of 1-10 MW, having artificial pressure vessels is a more flexible CAES technology that don't need to caverns and TES [35, 36]. This technology is suitable for a trigeneration purpose, including distributed electricity generation and storage, air-cycle heating and cooling in a combined process [98], which leads to a significant reduction in energy costs and greenhouse gas emissions in the coming future.

\subsection{Underwater/Ocean-CAES}

Underwater/ocean-CAES this storage system is a promising option in the absence of underground cavern, which can be integrated with 'offshore' renewable energy resources such as tides, wind and waves [31]. The compressed air is kept in an underwater air storage chamber installed on the seabed; the pressure of the compressed air is maintained constant requiring no pressure throttling, thus, allowing efficient release of energy from the compressed air. The authors in Ref. have planned constant-pressure CAES combined with pumped hydro storage, and conceptual design of ocean compressed air energy storage (OCAES), respectively. Also, an energy storage solution is patented by Hydrostat, based in Canada. This technology uses 'semiadiabatic' underwater-CAES (UW-CAES) with a potential to store large-scale electricity for around 4-48 h, at applications between 1 and $50 \mathrm{MW}$ [37]. UW-CAES is promising for prospect applications of micro grids and DERs. It is also projected to be delivered at optimal costs for the intended markets.

\section{The Current Development of CAES Technologies}

The drive for evolving CAES technology is actually to achieve sustainable energy and to decrease emissions, so current technology development target is to avoid using fossil fuel in CAES systems. Table 4 shows simple comparison of different CAES technologies currently under progress and developments, which improve the thermal process and incorporate CAES with other subsystems to improve system efficiency [10].

Table 4. Comparison of various CAES technologies [10].

\begin{tabular}{llllll}
\hline Technology & $\begin{array}{l}\text { Energy Density } \\
\text { (Wh/L) }\end{array}$ & $\begin{array}{l}\text { Power Rating } \\
\text { (MW) }\end{array}$ & $\begin{array}{l}\text { Storage } \\
\text { Duration }\end{array}$ & $\begin{array}{l}\text { Lifetime } \\
\text { (Years) }\end{array}$ & $\begin{array}{l}\text { Discharge } \\
\text { time }\end{array}$ \\
\hline Large CAES & $2-6$ & $110 \& 290$ & Hours-months & $20-40$ & $1-24+\mathrm{h}$ \\
AA-CAES & $2-6$ & $110 \& 290$ & Hours-months & $20-40$ & $1-24+\mathrm{h}$ \\
LAES & $8-24$ & $0.3 \& 2.5$ & - & $20-40$ & $1-12+\mathrm{h}$ \\
SC-CAES & $8-24$ & $110 \& 290$ & Hours-months & $20-40$ & $1-24+\mathrm{h}$ \\
Small CAES & $2-6$ & $0.003 \& 3$ & Hours-months & $23+$ & - \\
Up to-hour & Test 30,000 \\
\hline
\end{tabular}

Abbreviations: AA-CAES, Advanced Adiabatic Compressed Air Energy Storage; LAES, Liquid Air Energy Storage; SC-CAES, Supercritical Compressed Air Energy Storage; Cycling times_-number of cycles.

\section{Advanced Adiabatic Compressed Air Energy Storage (AA-CAES)}

In a traditional CAES system, during compression process there is a huge amount of heat released to the atmosphere through coolers. During the expansion stages, a large amount of heat is required to enhance the power, which is obtained from combustion of fossil fuel (or any other heat resources) to increase the temperature of air inside the expanders to enhance the power capability. Therefore, the use of the compression heat reduce fossil fuel use and consequently improve the efficiency of the whole system [27, 28].

For an AA-CAES with thermal storage integration, heat released from compression stages can be stored in adiabatic containers and used again during the expansion stages. The basic working concept of AA-CAES is illustrated in Figure 7, from which it is clearly shown that the thermal storage is in use before the air enters the air reservoir.

Yang et al., reported that there is indirect relationship 
between the compression stage and the output power of the system. The fewer the compression stages that are utilized with the same expansion pressure, the greater the system output power will be; and the more expansion stages that are used with the same compression pressure, the more the output power of the air unit mass will be [29, 30]. Zhao et al., designed a dynamic model of the hybrid energy storage with wind and the simulation results showed that the power output can satisfy the load demand [31]. Compared with the original
CAES, there are additional heat exchanger units and storage units, which are the crucial parts of AA-CAES. Luo et al. built an AA-CAES model with a low-temperature thermal storage system, and the parameters of the whole system were adjusted by simulation study [32]. From the study of Liu et al., it is reported that the exhaust temperature is too high from the AA-CAES low pressure turbine, resulting in a lot of waste, and an approach was recommended for improvement of energy efficiency of AA-CEAS systems [33].

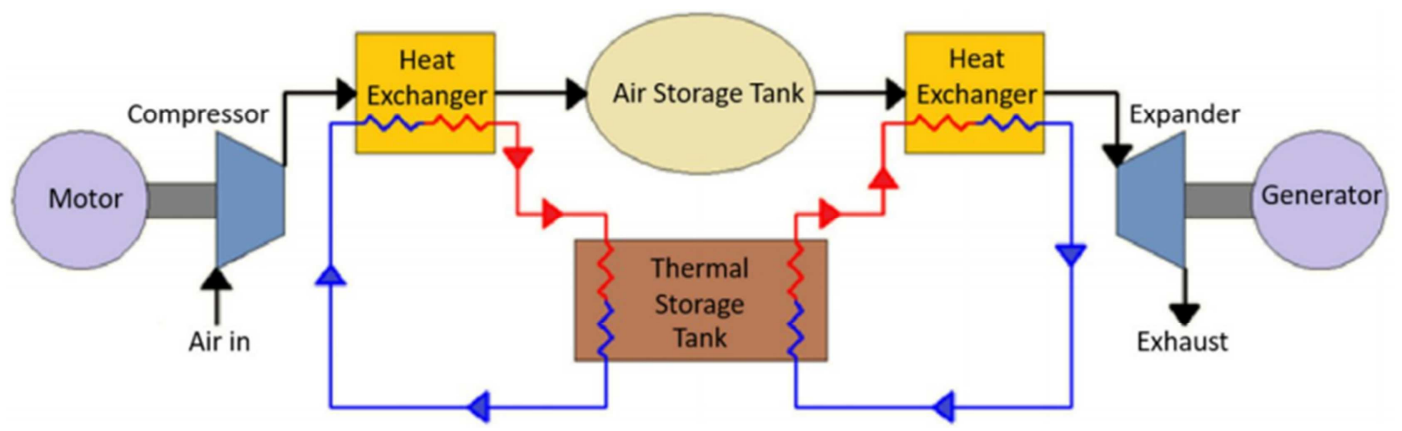

Figure 7. Schematic diagram of AA-CAES system [10].

Barbour et al., suggested the use of packed bed (PCB) heat exchangers as an alternative to indirect heat exchangers in the AA-CAES system, and the whole cycle thermal efficiency was claimed up to be $70 \%$ with the energy stored and utilized by the cascades structure [34]. Sciacovelli et al., constructed a dynamic model of the AA-CAES with PCB thermal energy storage, and then addressed the transient characteristics of the thermal energy storage stages, caves, compression and expansion stages and integrated system. The results revealed that the total system efficiency reached $70 \%$, when reservoir thermal efficiency reached $95 \%$ [35]. Tessier et al., designed a new type AA-CAES with cascades of phase change materials (PCMs) to improve system efficiency and $85 \%$ efficiency is shown by the simulation results [36].

\section{Applications of CAES Recently}

The application prospects and the potential of CAES in supporting power system operation have been widely documented. It is expected to play more and more important role in the energy management and development of the time of separation between generation and the usage of power. The potential applications of CAES are commonly considered twofold: suppliers and consumers (behind the meter). For the power supply side, the transmission and distribution network operators can utilize CAES for bulk energy rescheduling for maintaining the load balance. In addition, the users can use CAES to control the electricity usage obtained from the suppliers based on the energy price to reduce their energy bill. The potential applications of CAES are discussed below.

\subsection{Peak Shaving and Demand Side Management}

For electric power enterprises, peak shaving means the process of storing energy during off-peak periods and compensating electrical power generation shortfalls during the periods of high demand. In the different price tariff periods associated to the peak and off-peak durations, users can use CAES to manage the demand side energy by storing energy at the lower price and releasing the stored electrical energy during the periods of higher electricity price. In this way, the consumers can reduce their electricity costs. Considering the durations of long and medium term storage, Wang et al., established a demand response dynamic analysis model, which can help the owners of CAES design a target incentive mechanism that can attract the support at the project development early stage and also estimate the potential operation revenue generation [38]. Li et al., established an optimal time-of-use pricing response model, which can improve the load curve and obtain better resolution for load shifting effectively which is verified by many tests [39].

\subsection{Integration of More Renewable Power Generation Plants}

CAES can support the seamless integration of renewable power generation plants into the existing power network to realize the goal of stable power grids, which can help solve the problems of the inherent intermittence and instability of renewable power generation [40]. In the micro-grid concept, CAES can rapidly suppress the micro-grid power fluctuations and improve power supply quality, which is important for the reliable operation of micro-grids [41, 42]. Tang et al., established a simulation and experimental platform, including energy storage, photovoltaic, asynchronous wind turbines and typical load in micro-grids. The results from their study showed that effective control of energy storage could help micro-grids maintain good voltage and frequency stability during the switching process patterns of off-grid/grid pattern [43]. 


\subsection{Applications to Smart-Grids and Wind Energy Network}

Smart-grids, as the future direction and trend of the electric power industry, aim to achieve energy management in both directions, that is, from both supply and consumption with the support of internet and big data technology [44, 45]. Traditionally, consumers have passively accepted the electricity supplied to them so it is a direction of supply and consumption relationship; however, smart-grids will transform this structure by involving the active selection of supply, integration of local generation and dispatching energy storage sources. Rifkin, a famous American economist, believed that energy internet would be the core in the third industrial revolution, which will have a great influence on the development of society [46]. The energy internet is called smart-grid V2.0 by Li, et al., and energy storage is thought to be as the main enabling technologies of energy conversions and their integrated applications [2].

\subsection{Applications to Compressed Air Engines}

The compressed air energy can be converted into other different forms of mechanical energy through compressed air engines as in air-powered vehicles [47, 48]. Chen et al., performed a detailed a recent review on the advances in research and development of air-powered vehicles and revealed that the current work should be based on the principle and the structure optimization of air-powered automobile engines, the distribution forms and the reducing pressure technology [49].

\subsection{Applications in Other Fields}

In the case of power supply system failure, CAES systems can be used as a back-up power or uninterrupted power supply (UPS), which can supply adequate power to important users, such as banks, data processing centers, hospitals and other important sectors $[6,19]$. CAES systems could provide the capacity of black-start in a power shutdown condition. For example, the Huntorf plant offers black-start power to the nuclear units located near the North Sea [49].

\section{Conclusions}

The paper explained the types of energy storage systems with interest in mechanical energy storage. This review focused on the operating principles and concepts of CAES and presented a detailed comprehensive review on CAES technology development. The paper discussed the basic and vital information for CAES description, design, challenges and developments. This paper covers the importance of CAES, the recent advances in materials and information in CAES development and efforts recently. The following conclusions are made

1) The most basic Conventional CAES technologies are suitable commercially for large-scale applications. However, they face some challenges as they require certain geological formations and fossil fuels.

2) The utilization of waste heat generated by air compression process for air expansion is expected to offer an emission-free storage solution, by reducing the need for fossil fuels. This technology offers a much better system efficiency therefore recommending adiabatic-CAES for micro grids recently. However, further research is required for their extensive applications in the future. System efficiency of $70 \%$ is being achieved by RWE Power for its AA-CAES plant.

3) Small-medium scale CAES is also a promising development of CAES technology; it eliminates the need for geological formations. This technology is expected to thrive in the near future because of its trigeneration capacity, which reduce carbon emissions and energy costs, and improve distributed electricity generation.

\section{Recommendations for Future}

From the previous review it is recommended;

1) To utilize Compresses air energy storage in large scale systems as it provides reasonable efficiency however it faces some challenges.

2) To use advanced CAES technologies to overcome the common challenges as emissions that may harm the environment and the consumption of fossil fuels.

3) Using advanced CAES technologies is recommended to get better thermal process and better system efficiency.

4) Advanced CAES technologies can be integrated with reasonable intermittent energy plants to give stable grids and overcome the intermittent renewable sources.

5) CAES can be converted into other forms of mechanical energy in addition to its use as backup power.

6) To utilize efficient and cost effective Adiabatic CAES in micro grids as they provide an emission-free storage appliance.

7) Use isothermal technology as they improve RTE of 70$80 \%$ with low cost so they have economic advantage over conventional CAES.

8) In absence of caverns it is better to use small-medium CAES technology especially for a tri-generation purpose due to its flexibility with no need for certain geological configurations.

\section{Nomenclature}

$\begin{array}{ll}\text { IEA } & \text { International Energy Agency } \\ \text { MTOE } & \text { Million Tonnes of Oil Equivalent } \\ \mathrm{CO}_{2} & \text { Carbon dioxide } \\ \text { CAES } & \text { Compressed air energy storage } \\ \text { MESS } & \text { Mechanical energy storage systems } \\ \text { MW } & \text { Mega Watt } \\ \text { PHES } & \text { Pump hydro energy storage } \\ \text { FES } & \text { Flywheel energy storage } \\ \text { RES } & \text { Renewable energy storage system } \\ \text { TES } & \text { Thermal energy storage system } \\ \text { ACAES } & \text { Adiabatic compressed air energy storage } \\ \text { AACAES } & \text { Advanced adiabatic-CAES }\end{array}$




$\begin{array}{ll}\text { ICAES } & \text { Isothermal CAES } \\ \text { OCAES } & \text { Ocean compressed air energy storage } \\ \text { UW-CAES } & \text { Underwater-CAES } \\ \text { LAES } & \text { Liquid Air Energy Storage } \\ \text { SC-CAES } & \text { Supercritical Compressed Air Energy Storage } \\ \text { PCB } & \text { Packed bed heat exchangers } \\ \text { PCMs } & \text { Phase change materials } \\ \text { UPS } & \text { Uninterrupted power supply } \\ \text { RTE } & \text { Round trip efficiency }\end{array}$

\section{References}

[1] Aneke, M. and M. Wang (2016). "Energy storage technologies and real life applications - A state of the art review." Applied Energy 179: 350-377.

[2] Lovell J. Biofuels: Europe's 2nd-biggest coal-fired power plant will turn to wood from North America. E \& E Publishing, LLC; 2013. Available at: Available from: www.eenews.net.

[3] EC Biomass. Biomass fuel pellets. EC Biomass; 2015. Available at: Available from: www.ecbiomass.co.za].

[4] Mahlia TMI, Saktisahdan TJ, Jannifar A, Hasan MH, Matseelar HSC. A review of available methods and developments on energy storage; technology update. Renew Sustain Energy Rev 2014; 33: 532-45.

[5] Kousksou T, Bruel P, Jamil A, El Rhafiki T, Zeraouli Y. Energy storage: application and challenges. Sol Energy Mater Sol Cells 2013; 120: 59-80.

[6] Castillo A, Gayme DF. Grid-scale energy storage applications in renewable energy integration: a survey. Energy Convers Manage 2014; 87: 885-94.

[7] SBC. SBC energy institute analysis based on US DOE energy storage program planning document, 2011.

[8] Khodadoost Arani AA, Karami H, Gharehpetian GB, Hejazi MSA. Review of flywheel energy storage systems structures and applications in power systems and microgrids. Renew Sust Energ Rev 2016; 69: 9-18. https://doi.org/10.1016/j.rser. 2016.11.166.

[9] Guezgouz Mohammed, Jurasz Jakub, Bekkouche Bennaissa, Ma Tao, Javed Muhammad Shahzad, Kies Alexander. Optimal hybrid pumped hydro-battery storage scheme for off-grid renewable energy systems. Energ Convers Manage 2019; 199: 112046. https://doi.org/10.1016/j.enconman.2019.112046.

[10] Mahmoud, M., et al. (2020). "A review of mechanical energy storage systems combined with wind and solar applications." Energy Conversion and Management 210.

[11] S. M. Mousavi, F. Faraji, A. Majazi, K. Al-Haddad, A comprehensive review of Flywheel Energy Storage System technology, Renew. Sust. Energy Rev. 67 (2017) 477-490.

[12] Liu, W., et al. (2014). "Analysis and Optimization of a Compressed Air Energy Storage-Combined Cycle System." Entropy 16 (6): 3103-3120.

[13] Venkataramani G, Parankusam P, Ramalingam V and Wang J 2016. A review on compressed air energy storage - A pathway for smart grid and polygeneration. Renewable and Sustainable Energy Reviews 62. ScienceDirect, 895-907.
[14] Guney M S and Tepe Y 2017. Classification and assement of energy storage systems. Renewable and Sustainable Energy Reviews 75. ScienceDirect, 1187-97.

[15] Koohi-Fayegh, S. and M. A. Rosen (2020). "A review of energy storage types, applications and recent developments." Journal of Energy Storage 27.

[16] Fertig E, Apt J. Economics of compressed air energy storage to integrate wind power: a case study in ERCOT. Energy Pol 2011; 39 (5): 2330-42

[17] Diaz- Gonzalez F, Sumper A, Gomis-Bellmunt O, VillafafilaRobles R. A review of energy storage technologies for wind power applications. Renew Sustain Energy Rev 2012; 16: 2154-71.

[18] Zhang, X.; Chen, H.; Liu, J.; Li, W.; Tan, C. Research process in compressed air energy storage system: A review. Energy Storage Sci. Technol. 2012, 1, 26-40.

[19] Wasbari, F.; Bakar, R. A.; Gan, L. M.; Tahir, M. M.; Yusof, A. A. A review of compressed-air hybrid technologyin vehicle system. Renew. Sustain. Energy Rev. 2017, 67, 935-953 [CrossRef].

[20] Greenblatt, J. B.; Succar, S.; Denkenberger, D. C.; Williams, R. T.; Robert, H. S. Baseload wind energy: Modelingthe competition between gas turbines and compressed air energy storage for supplemental generation. Energy Policy 2007, 35, 1474-1492 [CrossRef].

[21] Pei, P.; Korom, S. T.; Ling, K.; He, J.; Gil, A. Thermodynamic impact of aquifer permeability on theperformance of a compressed air energy storage plant. Energy Convers. Manag. 2015, 97, 340-350 [CrossRef].

[22] Guo, C.; Zhang, K.; Li, C. Subsurface system design and feasibility analysis of compressed air Energy storagein aquifers. J. Tongji Univ. Nat. Sci. 2016, 44, 1107-1112.

[23] M. Budt, D. Wolf, R. Span, J. Yan, A review on compressed air energy storage: basic principles, past milestones and recent developments, Appl. Energy 170 (2016) 250-268.

[24] P. Krawczyk, Ł. Szabłowski, S. Karellas, E. Kakaras, A. Badyda, Comparative thermodynamic analysis of compressed air and liquid air energy storage systems, Energy 142 (2018) $46-54$.

[25] R. F. Abdo, H. T. C. Pedro, R. N. N. Koury, L. Machado, C. F. M. Coimbra, M. P. Porto, Performance evaluation of various cryogenic energy storage systems, Energy 90 (1) (2015) $1024-1032$.

[26] M. Antonelli, S. Barsali, U. Desideri, R. Giglioli, F. Paganucci, G. Pasini, Liquid air energy storage: potential and challenges of hybrid power plants, Appl Energy 194 (2017) 522-529.

[27] X. She, X. Peng, T. Zhang, L. Cong, Y. Ding, Preliminary study of Liquid Air Energy Storage integrated wit LNG cold recovery, Energy Procedia 158 (2019) 4903-4908.

[28] H. Peng, X. Shan, Y. Yang, X. Ling, A study on performance of a liquid air energy storage system with packed bed units, Appl. Energy 211 (2018) 126-135.

[29] C. Xie, Y. Hong, Y. Ding, Y. Li, J. Radcliffe, An economic feasibility assessment odecoupled energy storage in the UK: with liquid air energy storage as a case study, Appl. Energy 225 (2018) 244-257. 
[30] Bradbury K. Energy storage technology review. Duke University; 2010, p. 1-33.

[31] Young-Min K, Jang-Hee L, Seok-Joon K, Daniel F. Potential and evolution of compressed air energy storage: energy and exergy analyses. Entropy 2012; 14: 1501-21.

[32] Lim SD, Mazzoleni AP, Park J, Ro PI, Quinlan B. Conceptual design of ocean compressed air energy storage system. Proc Conf Oceans 2012: 1-8.

[33] Advanced adiabatic compressed air energy storage (AACAES). Energy Storage Association; 2013.

[34] ADELE-adiabatic compressed-air energy storage for electricity supply. RWE Power; 2010.

[35] Chen H, Zhang X, Liu J, Tan C. Compressed air energy storage. InTechOpen 2013: 101-12.

[36] Grazzini G, Milazzo. A thermodynamic analysis of multistage adiabatic CAES. Proc IEEE 2012; 100 (2): 461-72.

[37] Underwater compressed air energy storage: Islands and microgrids. White paper. Hydrostor; 2014. p. 1-13.

[38] Wang, B.; Yang, X.; Yang, S. Demand response performance and potential system dynamic analysis based onthe long and medium time dimensions. Proc. CSEE 2015, 35, 6368-6377.

[39] Li, C.; Xu, Z.; Ma, Z. Optimal time-of-use electricity price model considering customer demand response. Proc. CSUEPSA 2015, 27, 11-16.

[40] Ghalelou, A.; Fakhi, A. P.; Nojavan, S.; Majidi, M.; Hatami, H. A stochastic self-scheduling program forcompressed air energy storage (CAES) of renewable energy sources (RESs) based on a demand responsemechanism. Energy Convers. Manag. 2016, 120, 388-396 [CrossRef].
[41] Yang, X.; Su, J.; Lv, Z.; Liu, H.; Li, R. Overview on microgrid. Proc. CSEE 2014, 34, 57-70.

[42] Lu, Z.; Wang, C.; Min, Y.; Zhou, S.; Lv, J.; Wang, Y. Overview on microgrid research. Autom. Electr. Power Syst. 2007, 31, 100-107.

[43] Tang, X.; Deng, W.; Qi, Z. Research on Gridconnected/islanded seamless transition of microgrid based onenergy storage. Trans. China Electrotech. 2011, 26, 279284.

[44] Zhang, D.; Miao, X.; Liu, L.; Zhang, Y.; Liu, K. Research on development strategy for smart grid big data. Proc. CSEE 2015, 35, 2-12.

[45] Wang, C.; Sun, W.; Yi, T.; Yan, Z.; Zhang, Y. Review on energy storage application planning and benefit evaluation methods in smart grid. Proc. CSEE 2013, 33, 33-41.

[46] Rifkin, J. The Third Industrial Revolution: How Lateral Power Is Transforming Energy, the Economy, and the World, 3rd ed.; Palgrave Macmillan: New York, NY, USA, 2011; pp. 107-161.

[47] Chen, Y.; Xu, H.; Tao, G.; Wang, X.; Liu, H.; Jia, G. Research and progress of the compressed air power vehicle. Chin. J. Mech. Eng. 2002, 38, 7-11 [CrossRef].

[48] Xu, H.; Yu, X.; Wang, L.; Fang, Y.; Fan, Z.; Dou, W.; Li, D. Exergy analysis on compressed air engine. Trans. Chin. Soc. Agric. Eng. 2016, 32, 42-49.

[49] Raju, M.; Khaitan, S. K. Modeling and simulation of compressed air storage in caverns: A case study of theHuntorf plant. Appl. Energy 2012, 89, 474-481 [CrossRef]. 